\title{
Perceptions of Risky Play among Kindergarten Teachers in Norway and China
}

\author{
Junjie Liu' ${ }^{1}$. Åsta Birkeland ${ }^{2}$
}

Accepted: 19 December 2021 / Published online: 23 January 2022

(c) The Author(s) 2022

\begin{abstract}
Risky play provides multiple benefits for children's development. This study compared teachers' perceptions of risky play in one kindergarten in Norway and one in China, including the concept of risky play, the roles of teachers, the protective strategies adopted, and the factors limiting the practice of risky play. The aim of the article is to identify how teachers perceive risky play in different cultures and broaden our knowledge of what risky play is. The research question is: How do teachers from different cultures perceive different aspects of risky play? The study employs a risk "thermostat" model (Adams, 2001), drawing on teachers' perceptions of individual propensity to risks, perceived danger, potential rewards, and accidents in children's risky play. Semi-structured interviews with ten employees revealed that teachers in the two participating kindergartens had different perceptions of risky play. Findings indicated that teachers in the Norwegian kindergarten have theoretical and practical experience of understanding risky play within their cultural background. Guided by the kindergarten philosophy (rules or guidelines that kindergartens should follow, such as letting go of children and encouraging risky play), kindergarten teachers in Anji (a county in China) have learned a little about risky play and are gradually developing their views on it in practice. Teachers in both kindergartens support children's risky play, although in different ways and with different perceptions. This study contributes information on the differences in risky play across countries with diverse cultures.
\end{abstract}

\begin{abstract}
A Sincere Thank You To All the Teachers of the Norwegian and Chinese Kindergartens Who Participated in This Study for Their Patience During the Interviews. Sincere Thanks Also To My School and Supervisor for All the Support I Received. I Sincerely Thank Teachers and Classmates at the Western Norway University of Applied Sciences for Communicating With Me and Giving Me Different Perspectives, Inspiration, and Support. Thank You, ERASMUS,+ Global Mobility Program and UTFORSK Program for Their Generous Scholarship.
\end{abstract}

Junjie Liu

liujunjie85@outlook.com

1 Macquarie School of Education, Macquarie University, Sydney, Australia

2 Department of Pedagogy, Religion and Social Studies, Western Norway University of Applied Sciences, Bergen, Norway 
Keywords Risky play $\cdot$ Norway and China $\cdot$ Teachers' roles $\cdot$ Risk and safety $\cdot$ Early childhood education

\section{Résumé}

Les bienfaits des jeux risqués sur le développement de l'enfant sont nombreux. Cette étude compare les points de vue des enseignants au sujet des jeux risqués dans deux écoles maternelles, l'une en Norvège et l'autre en Chine, et aborde le concept même du jeu risqué, les rôles des enseignants, les stratégies de protection adoptées, ainsi que les facteurs limitant la pratique du jeu risqué. L'objectif de cet article est d'identifier la manière dont les enseignants perçoivent le jeu risqué selon les cultures et d'approfondir notre connaissance sur le sujet. La recherche s'articule autour de la question suivante : Comment les enseignants issus de cultures différentes perçoiventils les divers aspects du jeu risqué ? L'étude utilise le modèle du «thermostat » du risque (Adams, 2001), en s'appuyant sur la manière dont chaque enseignant perçoit le risque, le danger, les récompenses potentielles et les accidents liés aux jeux risqués. Des entrevues semi-structurées avec dix employés ont révélé que les enseignants des deux écoles maternelles en question avaient une vision différente du jeu risqué. Les résultats ont montré que les enseignants de l'école maternelle en Norvège ont des connaissances théoriques et pratiques du jeu risqué au sein de leur environnement culturel. Guidés par la philosophie de l'école maternelle (règles et directives des écoles maternelles à suivre, telles que donner de la liberté aux enfants et les encourager à prendre part aux jeux risqués), les enseignants de cette école du district d'Anji ont appris les rudiments du jeu risqué et développent peu à peu leur opinion grâce à la pratique. Les enseignants des deux écoles maternelles encouragent les jeux risqués, bien que l'approche et les perceptions soient différentes. Cette étude apporte des informations sur les différences en matières de jeux risqués dans divers pays aux cultures différentes.

\section{Resumen}

El juego de riesgo proporciona múltiples beneficios para el desarrollo de los niños. En este estudio se compararon las percepciones de los docentes sobre el juego de riesgo en un jardín de infancia en Noruega y uno en China, incluido el concepto de juego de riesgo, los roles de los docentes, las estrategias de protección adoptadas y los factores que limitan la práctica del juego de riesgo. El objetivo del artículo es identificar cómo los docentes perciben el juego de riesgo en diferentes culturas y ampliar nuestro conocimiento de lo que es el juego de riesgo. La pregunta de investigación es: ¿Cómo perciben los docentes de diferentes culturas los diferentes aspectos del juego de riesgo? En el estudio se emplea un modelo de "termostato" de riesgo (Adams, 2001), basándose en las percepciones de los docentes sobre la propensión individual a los riesgos, el peligro percibido, las recompensas potenciales y los accidentes en los juegos de riesgo de los niños. Las entrevistas semiestructuradas con diez empleados revelaron que los docentes de los dos jardines de infancia participantes tenían diferentes percepciones del juego de riesgo. Los resultados indicaron que los docentes del jardín de infancia noruego tienen experiencia teórica y práctica en la comprensión del juego de riesgo dentro de su entorno cultural. Guiados por la filosofía del jardín 
de infancia (reglas o pautas que deben seguir los jardines de infancia, como dejar ir a los niños y fomentar el juego de riesgo), los docentes del jardín de infancia de Anji (un condado de China) han aprendido un poco sobre el juego de riesgo y están desarrollando gradualmente sus puntos de vista sobre él en la práctica. Los docentes de ambos jardines de infancia apoyan el juego de riesgo de los niños, aunque de diferentes maneras y con diferentes percepciones. Este estudio aporta información sobre las diferencias en el juego de riesgo entre países con diversas culturas.

Outdoor play provides open-ended, dynamic, varied opportunities which are unpredictable and, at times, risky. However, the risks and challenges of being outdoors provide rich opportunities for learning, problem-solving, and developing social competence (Greenfield, 2004). Brussoni et al. (2015) found that the overall positive health effects of increased risky outdoor play provide greater benefit than the health effects associated with avoiding such play. In recent years, however, there has been growing concern that, as many western societies become increasingly risk-averse, children's freedom in outdoor play will be restricted, and many everyday activities that previous generations took for granted are now seen as dangerous and need to be avoided or regulated through overprotective safety measures (Little, 2010). Sandseter and Sando (2016) indicated that there is an increasing focus on safety and that children's risky play is increasingly restricted, even in a country such as Norway, which has been regarded as one of the least risk-averse in terms of children's play. Childhood is a time for learning and exploring, and children and young people should not be wrapped in cotton wool (Ball et al., 2008). Children need and want to take risks when they play (Ball et al., 2008). Play provision aims to respond to these needs and wishes by offering children stimulating, challenging environments to explore and develop their abilities (Ball et al., 2008).

In the Norwegian culture, encountering challenges and risks, particularly by spending time in nature, has been looked upon as an important part of growing up and becoming a sensible and well-functioning human being (Sandseter et al., 2012). In Chinese society, the small number of children per family has led parents to be overly concerned about their safety (Frost et al., 2015). The slightest bump in kindergarten can result in parents being unforgiving to the childcare facility involved and, in serious cases, resorting to legal action. Kindergarten teachers in China are perpetually "walking on thin ice" and have to sacrifice children's opportunity to participate in risky play and even exploratory activities for the sake of their safety, thus overprotecting and confining them (Frost et al., 2015). Therefore, comparing Chinese and Norwegian kindergarten teachers' perceptions of risky play can reflect different perspectives in different cultural contexts. On the other hand, the development of teachers' practice cannot be separated from the guidance of theory. Exploring teachers' knowledge and understanding of risky play can provide directions for future teacher learning and training, and better promote the practice. More importantly, it can provide perspectives that challenge established practices and broaden our understanding of risky play by "confronting"/revealing two different systems. 
In the following sections, we discuss relevant studies and the research gap that we intend to cover. We develop the theoretical perspective of this study and describe what questions the study aims to solve; subsequently, we present the methodological and analytical approaches selected. In the findings section, we present teachers' definitions of risky play, their roles in risky play, their strategies to balance risk and safety, and the factors they have found that limit the degree to which they can support risk-taking behaviors. The discussion section considers how teachers' perceptions are reflected in practice and in different cultures. Finally, we discuss the implications and limitations of the study.

\section{Literature Review}

\section{The Concept of Children's Risky Play}

Children's risk-taking behavior in play has been studied since the 1970s, but consensus on a definition remains limited. However, the literature shows that children's risk-taking behavior in play has common characteristics across cultures. Generally speaking, research shows that risk-taking behavior in play imitates risks taken in real life (Aldis, 2013). Sawyer (1994) pointed to a possible scenario in which risky play might occur, namely when children's skills exceed the challenges provided by the available equipment. Naturally, children try to reduce the dullness and increase the challenge of the equipment. For example, they attempt to make swinging more challenging by standing up in the swing, jumping out of the swing, twisting the chains, or bumping into another child who is swinging (Sawyer, 1994). For Stephenson (2003), the important factors in what makes a physical experience risky for a four-year-old child seem to be attempting something never done before, feeling borderline "out of control," often because of height or speed, and overcoming fear. As related to the possibility of injury and feelings of fear, risky play is defined as play that makes children experience fear. Greenfield (2004) asked four-year-old children to convey their feelings and views about the outdoor playground. Favored areas were the bikes, swings, and "zip-wire" which had common features- "risk, speed, excitement, thrills, uncertainty, and challenge (Greenfield, 2004)." One study (Little \& Wyver, 2008) suggested that risky play might be defined as play that provides opportunities for challenge, testing limits, exploring boundaries, and learning about risk of injury. Sandseter (2009a) explicitly proposed that risky play can generally be defined as thrilling and exciting forms of play that involve a risk of physical injury. Tovey (2010) further expanded risky play into an outdoor, nature-based, thrilling, and exciting activity that includes some risk of injury, such as balancing, climbing, sliding, and hanging upside down. Although definitions of risky play vary, they include several of the same elements, namely challenge, excitement, fear, and risk of injury. Researchers have defined risky play based on their research data, while teachers learn from practice and form their own unique understanding of it. In the current study, we specifically examined teachers' perceptions of the concept of risky play to seek possible cultural differences and broaden our understanding of risky 
play practice. Teachers' definitions reflect their beliefs and attitudes toward outdoor risky play, which are highly associated with how they understand children's play.

\section{The Impact of Theory on Teacher's Beliefs About Risky Play}

Few researchers have conducted comparative studies of risky play and teachers' perceptions in kindergartens in different cultural contexts. Perceptions of risk are largely influenced by cultural factors. Little et al. earlier (2012) explored cultural differences in risky play by comparing children's outdoor play experiences and early childhood educators' attitudes toward risk in play in Australian and Norwegian early learning centers. Using semi-structured interviews with 17 staff members from six early learning centers in Australia and 14 staff members from four early learning centers in Norway, the researchers found that the two countries shared beliefs about the definition and importance of risky play, but that there were differences in the way these beliefs were translated into practice (Little et al., 2012). Although both groups of practitioners experienced barriers in translating beliefs into practice, these barriers appeared more significant for the Australian practitioners and were, in the main, factors outside their direct control (litigious environment, regulatory requirements, and quality of outdoor environment) (Little et al., 2012).

The researchers also explored whether differences in the theoretical underpinnings from early childhood education in Norway and Australia might impact risktaking play. The results showed that the reasons that Norway has a strong commitment to risky play while Australia has succumbed to risk-averse pressures are multifaceted, complex, and likely to be rooted in a wide range of beliefs, practices, and policies in each country. Although teachers in Australia and Norway have similar levels of training and theoretical knowledge, Norwegian practitioners, who emphasize Gibson-based (Gibson, 1988) approaches and dynamic systems theory, may be more consistent in their beliefs and practices in regard to risky play than their Australian counterparts (Sandseter et al., 2012).

McFarland and Laird (2018) found that most educators in the US and Australia thought it was important for children to be provided with opportunities for outdoor risky play and did indeed provide appropriate activities. However, educators in Australia rated outdoor risky play opportunities as significantly more important than educators in the US. Comparative studies have principally focused on teachers' beliefs or perceptions in Western countries. This study aims to build on previous research and fill the gap by exploring teachers' perceptions in countries, which belong to different cultures, such as western and eastern countries.

\section{Benefits of Risky Play}

Risky play has multiple benefits for the physical, cognitive, and social development of young children. Risk-taking in play helps children test their physical limits, develop their perceptual-motor capacity, and learn to avoid and adjust to dangerous environments and activities (Brussoni et al., 2012). Children can learn risk assessment and how to master risk situations, thus developing a sound sense of risk 
which may aid survival when, later in life, watchful adults are no longer present (Apter, 2007). Little (2006) found that if adults make decisions that deny children the opportunity to engage in risky activities, children are also denied the opportunity to learn about risk and how to evaluate risks. Risky play in natural outdoor environments offers opportunities to develop children's social competence. The interplay of communication, peer interaction, self-efficacy, and children's participation helps children to master experiences during risky play and, at the same time, helps them develop positive relationships with other children at kindergarten. When adults believe in the positive benefits of risky play, they are more inclined to encourage and support risk-taking in children's play (Orestes, 2015).

\section{Theoretical Perspective}

The benefits of outdoor risky play are so apparent that concerns are raised when children are denied such benefits due to barriers in practice. Identifying and overcoming such barriers is becoming critical (Beyer et al., 2015). As shown in Fig. 1, Adam's (2001) model has four factors: propensity to take risk, perceived danger, potential rewards, and accidents. It gives an overall picture of the factors impacting children's decisions to take risks in play situations. Individuals' risk propensity influences risktaking decisions. People with a high propensity to take risks will perceive the situation as less dangerous than people with a lower propensity to do so (Apter, 2007). As can be seen from Adams' (2001) model, an individual's perception of danger in risky play is also a crucial factor in risk-taking decisions. Children's propensity to take risks in play and their perception of danger in a situation is most likely influenced by their degree of sensation seeking. Therefore, differences from one child to the next can be expected (Sandseter, 2009b). Adams' (2001) model also suggests that the propensity to take risks is influenced by the potential related rewards and

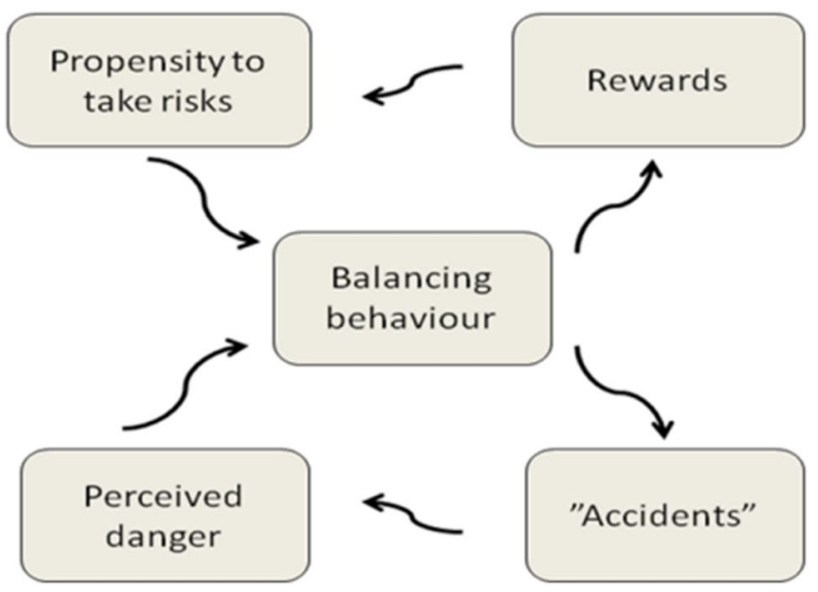

Fig. 1 The risk "thermostat" model by John Adams (2001) 
accidents. The risk-taking decision, as illustrated by Adams' (2001) model, is a continuous evaluation of the possible rewards weighed against the potential accidents. Children's past experiences of accidents in similar situations and their assessment of the potential severity of injury will influence their perception of risk, helping them decide whether to engage in risky play and, if they do so, how to enact it (Adams, 2001).

Adams (2001) pointed out that many risk-related decisions involving children are made by adults because children are generally under adult surveillance. Therefore, children's risk-taking decisions are also influenced by supervising adults' evaluations of the risky situation and their decision to act when children take risks in play. All these factors interact with and influence each other and individuals' risk-taking decisions (balancing behavior).

Teachers have a role to play in the provision of outdoor risky play for children, especially as it concerns access to the risk-taking environment. The value teachers place on the outdoor environment is vital to young children's outdoor experiences. Teachers bring their own beliefs and values to the outdoor play environment, and these directly affect children's outdoor play (Renick, 2009). Teachers are concerned about children's safety and have fears about risk-taking, even though they support risky play (Bilton, 2020). As teachers play crucial roles in developing children's risk-taking decisions in regard to outdoor play and engagement, it is vital to understand their perceptions of outdoor play as a way to promote risky play and the physical and emotional wellbeing of young children.

\section{The Present Study}

This study is an exploration of teachers' perspectives of risky play, in which different ideas from different perspectives collide, reflect, and learn from each other. This study explores the following questions:

(a) How do teachers in different cultural contexts define risky play?

(b) What roles do teachers in different cultural contexts think they should play in risky play?

(c) What measures do teachers in different cultural contexts take to ensure children's safety during risky play?

(d) What limitations do teachers in different cultural contexts see in practicing risky play?

\section{Method}

\section{Participants}

For the Norwegian study, the researchers approached a private kindergarten in Bergen, Norway, founded with parental investment, and invited it to participate. Five teachers with teaching experience ranging from one and a half years to 12 years 
were selected as the interviewees, including teachers with different backgrounds, teachers of children aged between three and six, and teachers of infants from birth to three years old. In China, the participants were five teachers of classes of different age ranges $(3-4,4-5$, and 5-6) and different periods of teaching experience (1-12 years) from a public kindergarten in Anji county, which is famous for "Anji play". Anji play is an outdoor, integrated play characterized by movement, where the teacher returns the right to play to the children. Children can climb fixed facilities, such as frames, play with sand and water, and mix paints to paint the walls. They can also use tires, boards, ladders, etc. to build their play. Risk-taking is supported, and children can choose challenges on their own terms, in their own time, and where they want. The Chinese kindergarten which participated in this study thus experiments with risky play. These two kindergartens were selected because they have both similarities and differences. They both support children's risky play and have rich experience in practicing risky play, and the teachers give the children some space and rights. However, the teachers' education, upbringing, and cultural environment are very different.

\section{Interviews}

The interviews were semi-structured and included broad pre-determined questions that were formulated by the researcher, based on the purpose of the study, to gain insight into teachers' perceptions of the concept of risky play, teachers' roles in risky play, protective strategies, and limiting factors. However, the wording of the questions was flexible, so the interviewer could follow-up on interesting statements from the participants. Sample questions included "How do you define risky play?", "Describe your roles in risky play", "What do you do to protect children in risky play?", and "Explain why you feel that there are barriers in practicing risky play (if they indicate this)."

A researcher familiar with the Mandarin and English languages conducted separate interviews with Chinese and Norwegian teachers, in English and Chinese, for approximately one hour each. After the interview, the researcher was responsible for translating Chinese into English and transcribing the transcripts.

\section{Data Analysis Procedures}

A content analysis of the interview data was conducted to identify the similarities and differences between teachers' perceptions of risky play, how to deal with the dangers, and what barriers they met in practice. The analyses were also based on the four factors in Adams' (2001) model to explore children's risk-taking decisions and risk management and then to gain a deeper understanding of teachers' perceptions and practice of risky play. This study used NVivo12Plus software to sort, analyze, and code the data. We read the texts thoroughly and coded them thematically in three stages. In stage 1, we read the transcripts to gain a sense of the whole picture with an open mind. Then, we extracted the interviewer's own words from the interview text, for example, "risky play is challenging." In stage 3, we categorized the 
codes into broader clusters by theme, for example, "definition of risky play." Two independent researchers reviewed each category once more to ensure the coding was consistent.

\section{Ethics}

Data were collected for this study with the consent of the participants, whose integrity, safety, and right to anonymity was respected at all times. We guarantee participants' privacy in this study, and all names in the paper are pseudonyms. Participants had the right to withdraw from the study at any time without any repercussions. The University Committee on Human Research Protection from East China Normal University gave ethical approval of the study, and the Norwegian kindergarten gave us permission according to their ethical standards.

\section{Findings}

The four major themes that emerged from the data analysis-those which most directly address the research questions - are shared below. These themes are teachers' perceptions of the concept of risky play; teachers' roles; strategies teachers take in risky play; and the barriers they perceive. The table below presents the percentage of participants who discussed each code in the theme. The study quotes the teachers' original words to demonstrate their views better.

\section{Perceptions of the Concept of Risky Play}

Teachers are practitioners of kindergarten philosophy and providers of materials. Their concepts play a decisive role in the practice of risky play. The following table shows the kindergarten teachers' perception of risky play concepts. The percentage represents the frequency proportion of each code mentioned by the teachers in the original interview data (Table 1).

\section{Differences in Teachers' Perceptions of Risky Play Based on and in the Absence of Theoretical Contexts}

It can be seen from the above table that the kindergarten teachers have different understandings of risky play. The Norwegian kindergarten teachers have a certain theoretical basis for risky play, and their understanding of risky play is based on a combination of theory and practice. Norwegian teachers $(20 \%)$ said they had learned Sandseter's (2009a) theories of the concepts, classifications, and characteristics of risky play at school and that practicing risky play in kindergarten contributed to their developing a unique perception and understanding of such play as a risk with a reward. Moreover, $40 \%$ saw the benefits or rewards for children even though it may be risky. Eighty percent of Norwegian teachers discussed the risk of 
Table 1 Kindergarten teachers' perceptions of the concept of risky play

\begin{tabular}{ll}
\hline Norway F Kindergarten & Anji X Kindergarten \\
\hline 1.1 Physical and psychological challenges (80\%) & 1.1 Factors of uncertainty (20\%) \\
1.2 Risk of injury (80\%) & 1.2 Highly challenging, highly probing (100\%) \\
1.3 Risk with reward (40\%) & 1.3 Risk factors (40\%) \\
1.4 Challenging (20\%) & 1.4 New play (60\%) \\
2.1 Sandseter's classification (Sandseter, 2009a) of & 2.1 Problem-solving capacity (20\%) \\
risky play (20\%) & 2.2 Enhanced self-protection capacity (40\%) \\
3.1 Children's perspective (40\%) & 3.1 Sense of accomplishment (60\%) \\
3.2 Children's preferences (40\%) & 3.2 Inner fear (100\%) \\
4.1 Different boundaries, perspectives of teachers & 4.1 Differences in individual experience (40\%) \\
(20\%) & 4.2 Physical risk-taking (100\%) \\
& 4.3 Psychological risk-taking (100\%) \\
& 5.1 Anji Play Keywords (60\%) \\
5.2 The materials are getting more difficult (20\%)
\end{tabular}

injury, while $40 \%$ of Chinese teachers referred to it. Children can get hurt, which Norwegian teachers think is hard to avoid, but children also learn the consequences of what they are doing and learn how to take care of themselves and what to do next time they are challenged. Norwegian teachers believe that children benefit from the risks. "Amy", for example, cited "learning to get used to different heights, speeds, like knowing that falling from a higher place will hurt more than falling from a lower place." Anji kindergarten teachers' understanding of risky play is based on the kindergarten's philosophy ("Grounded in love, risk, joy, engagement, and reflection, Anji Play returns the right of True Play to every child”). Thus, they encourage children to engage in risk-taking and observe the practice of letting go of children's play. Sixty percent of the Chinese teachers mentioned five keywords (love, risk, joy, engagement, and reflection) for kindergarten. They believe that children learn risky play from practice, and deepen their understanding of the concept of risky play in practice.

\section{Similarities in Teachers' Perspectives_Physical and Psychological Challenges to Children}

Although the teachers have different theoretical backgrounds, both groups mentioned that risky play is a physical and psychological challenge to children $(80 \%$ of Norwegian teachers and $100 \%$ of Chinese teachers). Norwegian teachers see risky play as a way for children to challenge themselves physically and mentally. As "Lily" said, "children may be physically able to do these activities, but they may find them mentally challenging. Some play may seem safe, but it requires children to use their bodies and overcome their fears." Teachers at Anji kindergarten regard risky play as physical and psychological risk-taking. All of them agreed that risky play is a highly challenging and highly probing activity. One teacher describing a case she experienced as supportive of children's need for physical and psychological risk-taking said, 
There's a girl in our class, Ran Ran. She went to the first position to try to play the zip-line, then she grabbed the pulley, she tried to slide over, she tried twice and backed up, then she tried again to go forward, and this time, suddenly, it worked. From the beginning to the end of the play, I could see a noticeable change in her expression: first, she was scared, and slowly I could see that she started to laugh. I've seen a shift from her psychological risk-taking to her physical risk-taking.

\section{Considering the Differences in Children's Perspectives and Individual Experiences}

Teachers in the two kindergartens analyzed their understanding of risky play from the perspectives and preferences of children (40\%) and differences in their individual experiences $(40 \%)$. They believed children themselves are the indicators to measure whether the play is risky. Norwegian teachers (40\%) believe that children's feelings and perspectives on play influence whether it is risky or not. "Krystal" gave the following example:

Once, I took the children to a park to play with the climbing facilities, and a boy was so scared that he cried when he saw it, and I took him by the hand and told him, 'Let's put you on the equipment, but you don't have to play now, you can play when you are ready, we can watch the other children play first.'

Differences in the individual perceptions and perspectives of children, when faced with the same facilities, are closely related to whether the play is risky. In addition, $20 \%$ of Anji teachers talked about teachers' perceptions. Different teachers set their boundaries and criteria for risky play. Anji kindergarten teachers take children's different individual experiences as a crucial basis to judge risky play. Teachers there believe that each child's experience is different, so the experience of risk-taking is also different for them. One teacher said,

There were individual differences in the play I observed. For example, jumping the box, for some children it was a challenge, children laid a lot of layers of mats on the ground, some children jumped far, some jumped close to the ground, jumping in different ways. Then there's climbing, carrying ladders to trees, some children standing on branches, some on ladders.

\section{Conclusion}

Almost half the Norwegian teachers defined risky play as physical and psychological challenges, risk of injuries, a risk with reward, and according to children's perceptions and preferences. Chinese kindergarten teachers also interpreted the risky play as highly challenging, highly probing, physical and psychological challenges, individual experiences, and involving risk factors. In addition, they mentioned, in particular, that risky play is a new type of play $(60 \%)$, that the materials will get more difficult for children $(20 \%)$, and that it is full of uncertainties $(40 \%)$, which may lead to the children being frightened (100\%). However, Chinese kindergarten 
teachers believed that it brings a sense of accomplishment (60\%) and enhances children's problem-solving (20\%) and capacity for self-protection (40\%).

\section{The Teacher's Role in Risky Play}

Teachers in both kindergartens mentioned that teachers should have multiple roles in risky play, and Norwegian teachers identified the following six roles: supporter $(80 \%)$, protector $(60 \%)$, role model $(60 \%)$, playmate $(60 \%)$, rule-maker $(20 \%)$, and home coordinator (20\%). Anji kindergarten teachers believed that teachers mainly have six roles: supporter $(100 \%)$, observer $(100 \%)$, protector $(100 \%)$, guide $(80 \%)$, participant $(40 \%)$, and sharer $(20 \%)$. Kindergarten teachers in China and Norway have diverse views on this, but agreed that supporters and protectors are important roles (Table 2). The following table presents the kindergarten teachers' role coding:

\section{Supporting Children's Risky Play with Companionship and Additional Materials}

The role of supporter was identified as important by teachers, and the ways in which teachers supported children's risky play varied. Norwegian teachers believe that to be around children is to give them the greatest support, and it is important for teachers to affirm and encourage children when they have done something that they have not done before or that makes them feel excited and challenged. "Lily" said, "with the teacher around, the children will feel safe, they trust teachers." All teachers in Anji kindergarten gave priority to being a supporter and providing support for the physical conditions of children's play, such as the addition of materials and ensuring time and opportunity. Teachers' support is significant, such as help and guidance, letting go, and only supporting children when they have run out of ways to manage or are in real danger. In addition, "Xiaoxi" presented a characteristic concept: "letting go of unease." On the one hand, the teacher has to let go of the child's play; on the other hand, the teacher's heart is always engaged, as they are always concerned for the safety of children.

\section{Different Ways of Protecting-Facing Risks, Observing, and Guiding}

Teachers believed that protecting children's safety is an important role, and they protect children's safety from different perspectives. Compared to $60 \%$ of Norwegian teachers, all $(100 \%)$ of the Anji teachers stressed the role of protector. While

Table 2 Kindergarten teachers' roles

\begin{tabular}{ll}
\hline Norway F Kindergarten & Anji X Kindergarten \\
\hline Supporter $(80 \%)$ & Supporter $(100 \%)$ \\
Protector $(60 \%)$ & Protector $(100 \%)$ \\
Playmate $(60 \%)$ & Participant $(40 \%)$ \\
Role model $(60 \%)$ & Guide $(80 \%)$ \\
Rule maker $(20 \%)$ & Observer $(100 \%)$ \\
Home coordinator $(20 \%)$ & Sharer $(20 \%)$ \\
\hline
\end{tabular}


Chinese kindergarten teachers tend to observe and guide children to avoid dangers at source, Norwegian kindergarten teachers value the shared play experience with children and their growth when they get bruised and scraped. "Melody" said, "of course, our duty is to protect them as much as possible. I don't think we are afraid of children being injured, because if they have bruises or lumps, they are usually fine. There are a few severe accidents in Norwegian kindergartens." All the Anji kindergarten teachers claimed that the primary task of teachers in risky play is to observe the moments of wonder, the potential safety hazards, and the difficulties children encounter. They felt that without observation, it was difficult for teachers to understand children's play, intervene in time to keep them safe, and communicate and share their play. Observation is the premise and guarantee of protecting children and understanding children's play in the first place.

\section{Conclusion}

The Norwegian kindergarten teachers focused on the roles of supporting, protecting, role modeling, and accompanying. They engaged in children's risky play and were a role model to encourage children to be part of such play. Notably, $20 \%$ saw the value of the roles of rule maker and home coordinator. They said teachers need to set rules to make sure children will not "get out of line." They also saw themselves as responsible for talking to parents about the injuries their children had suffered or their achievements in risky play. Anji kindergarten teachers placed great importance on the role of supporter, observer, protector, and mentor. They also considered engaging in and sharing children's play to be among teachers' roles.

\section{Strategies to Balance Risk-Taking and Safety}

The physical boundaries for children today have shrunk. Parents are afraid for their children's safety (White, 2016). The existence of two-income families has led to "latchkey children" who must stay indoors or go to supervised after-school activities (White, 2016). However, children do not need a planned, structured "safe" life, and an "imprisoned" childhood is unlikely to bring them happiness and joy. When children play outdoors, they interact with their surroundings, their peers, and their teachers, they go exploring and creating, undertaking activities that are difficult for teachers to anticipate and which, therefore, they cannot control (McGinnis, 2003). Nonetheless, teachers have control over identifying safety hazards and reflection after play. Adult control may be seen as a "protection" when it is necessary to prevent children from being exposed to risk, but as a "constraint" on their autonomy and a "source of risk" when it is not necessary (Kelley et al., 1998). Therefore, teachers need to balance risk and safety, and provide help to children at the right time.

Kindergarten teachers have integrated their own understanding into the strategies they implement to balance risk and safety. Norwegian kindergarten teachers rely heavily on the judgement of teachers and on giving children the opportunity to practice and deepen their awareness of risks. In Chinese kindergartens, 
teachers' observation of children and demand that they should learn self-protection dominate, and teachers focus on sharing and reflection. The following table shows kindergarten teachers' views on balancing risk and safety (Table 3).

\section{Observation is the Cornerstone of Teachers' Prediction}

Teachers' judgment is believed to be essential to balance risk-taking and safety by $100 \%$ of Norwegian kindergarten teachers. Kindergarten teachers in Norway believe it is necessary to observe the environment, be close to children in need, and help them out of dangerous situations. "Krystal" said, "if they climb up a tree or a wall, I try to get as close to them as possible so I can catch them when they fall. I always try to get close to the kids." Once teachers think that children are in danger, they will always be around them, ready to catch them if they fall from trees or roofs. At the same time, they do not let children play dangerously. "Johanna" said,

Children can always get hurt. But we don't allow them to do things that are too dangerous. For example, if they are going on a trip near the beach, we have a rule that they must wear a life jacket or something similar. And they can't get too close to the sea. It's too dangerous to let kids play on the beach in that situation.

In addition, teachers know the children well and can judge each child's abilities and level and help them accordingly. "Lily" said, "the teachers also make the children understand that they have to protect themselves, do their 'job' and be safe. When they shake the rope, for example, although the teacher is underneath, the children themselves must hold on to it and not let it go."

Teachers (60\%) in Anji kindergarten highlighted teachers' positions and the division of labor during play. Two Anji kindergarten teachers and a caregiver teacher work together to protect children by combining fixed-point and touring observation. At the same time, they all agreed that teachers should make a judgement before the children start playing and determine whether an action of the child will be dangerous. They should be prepared to protect the child by approaching him or her whenever the teacher discovers that there may be a danger. When children have safely passed that moment, the teacher takes a step back and observes their play.

Table 3 Kindergarten teachers' strategies to balance risk-taking and safety

\begin{tabular}{ll}
\hline Norway F Kindergarten & Anji X Kindergarten \\
\hline Teachers' judgment (100\%) & Teachers' sharing and reflection (100\%) \\
Teachers' requirements for children (20\%) & Teachers' observation and predictability $(100 \%)$ \\
Children's experience (40\%) & Children's self-protection and reflection $(40 \%)$ \\
& Teachers' positions and division of labor $(60 \%)$ \\
& Play environment and materials (60\%) \\
\hline
\end{tabular}




\section{Children are an Important Part of Assessing Risk and Safety}

Teachers regard children's experiences and teachers' requirements as critical parts of balancing risk and safety. Forty percent of the Norwegian kindergarten teachers believe that, as children's experiences become increasingly enriched, they have the opportunities to learn what the risk factors are. "Amy" gave an example: "Climbing rocks, climbing trees-they do these things every day, they get used to it, and they get experience, like knowing that what is dangerous." One hundred percent of the Anji kindergarten teachers believe that sharing self-protection methods with children is a vital strategy. Some teachers will discuss possible dangerous situations that may arise with children, as well as how they should protect themselves, before play starts. As the play progresses, the teacher also has individualized conversations about safety issues that arise for individual children. At the end of the play, the teachers share self-protection approaches with the help of photos or videos they have taken during the specific context of play. Teachers also reflect on and adjust their own behaviors and observations, for example, in regard to sudden dangers that the teacher had not been aware of.

\section{Conclusion}

The Norwegian kindergarten teachers mentioned three measures to balance danger and safety, which are, in descending order of importance, teacher judgment, children's experience, and teacher requirements. On the other hand, all the teachers in the Anji kindergarten emphasized teachers' sharing, reflection, observation, and predictability. More than half $(60 \%)$ referred to teachers' positions, division of labor, and play environment and materials. For example, they provide mats for children to fall or jump on and said that they check the play facilities from time to time to make sure nothing has gone wrong.

\section{Limitations in the Process of Practicing Risky Play}

The risky nature of risky play creates certain limitations for children's development, and kindergarten teachers consider personal factors, such as teachers' worries or fears, or parents' concerns, as detrimental to the development of risky play. Natural factors, such as weather conditions, are an obstacle to outdoor risky play in Chinese kindergartens. The following table shows the difficulties teachers have encountered in practicing risky play and what they perceive as possible limiting factors (Table 4).

\section{Personal Limitations in Risky Play}

Kindergarten teachers all mentioned personal factors that can limit the development of risky play. Some (40\%) of the Norwegian teachers discussed parental concerns; in contrast, $100 \%$ of the kindergarten teachers in Anji mentioned parents' lack of understanding. Forty percent of Norwegian teachers believe that some diseases can 
Table 4 Limiting factors during the practice of risky play

\begin{tabular}{ll}
\hline Norway F Kindergarten & Anji X Kindergarten \\
\hline Personal factors: & Personal factors: \\
Parental concerns $(40 \%)$ & Parents' lack of understanding (100\%) \\
Teachers' 'fear' $(40 \%)$ & Teachers' concerns $(20 \%)$ \\
Whether the child is healthy $(40 \%)$ & Natural factors: \\
& Bad weather (20\%) \\
\hline
\end{tabular}

affect children's risky play, such as "whether they have diseases or other things that make risky play riskier. If they have a disease, their bones are easily broken, and of course, you can't let that child stay in the tree for a long time." Teachers' consideration and "fear" also have an impact, according to $40 \%$ of the teachers in the Norwegian kindergarten and 20\% in the Anji kindergarten. However, "Amy" said, "the fact that a child falls encourages me to support risky play more, as it means that children need to be more involved in the play and become more confident." "Krystal," similarly, said "you cannot limit risky play just because of an accident. Teachers have to think about what's acceptable to them. There are indeed accidents in risky play, but very few." Teachers believe their "fear" is due to a sense of responsibility to children, and it is up to teachers whether to carry out risky play.

All Anji kindergarten teachers (100\%) mentioned that some parents did not understand when they started to practice risky play. However, after sustained effort from the teachers, most parents gradually understood and supported risky play.

I often send videos of play to the WeChat group and then write a paragraph about the phenomenon of children's play, which is what they are asking about. We also carry out an Anji play salon, where the family committee takes the lead and shares their experiences, for example, talking about what has happened to their children in the past two years. Parents communicating the changes that Anji play brings to their children is much more effective than teachers, so teachers should provide parents with opportunities to understand Anji play. Then they will support risky play from the kindergarten perspective.

In addition, teachers' concerns were mentioned only once in Anji kindergarten, but premature or inappropriate intervention in children's risky play due to teachers' excessive worry is also a huge barrier.

\section{Natural and Physical Limitations in Risky Play}

The Norwegian teachers use the changing weather as a way for children to learn about nature, and rain and snow do not limit their outdoor play. Instead, children go outside when it is raining or snowing to experience what it feels like to play in the rain or snow. As "Johanna" says, "if we don't let children go outside when it is raining or snowing, then they are not only missing out on the opportunity to be outdoors but also losing the right to experience nature." Twenty percent of the Anji kindergarten teachers said that extreme weather, such as smog, rain, or snow, could trap 
children indoors and make them lose out on different play experiences. On the one hand, this has to do with the social environment in China, where parents are worried that rain or snow will make their children catch a cold and put pressure on teachers and kindergartens. On the other hand, it has to do with the fact that children grow up in a protected environment and are used to hiding at home when it rains or snows outside.

\section{Conclusion}

The Norwegian teachers were only concerned about personal barriers, such as parental or teachers' concerns and children's health conditions. The Anji kindergarten teachers were also worried about extreme weather, such as rain, snow, or smog.

\section{Discussion}

In this study, despite the lack of a theoretical basis for risky play among Chinese teachers, both Chinese and Norwegian kindergarten teachers viewed it as a dual challenge that was beneficial to children's physical and mental health and included children's differences as indicators of risky play. In addition, Norwegian teachers believe that teachers' boundaries and perspectives can influence judgments about whether the play is risky or not, which is consistent with an earlier study. Even though there were some implicit rules, the practitioners usually made an individual evaluation of risky play in each play situation, considering each child individually according to the child's competence and risk mastery (Sandseter et al., 2012). Norwegian teachers believe risky play is a challenge to children's bodies and minds, which is a risk of reward. According to Adams (2001), the risk-taking decisions of young children involve individual risk management, which requires the individual to calculate the chance of being injured against the possible reward. Sandseter and Kennair (2011) also found that risky play is a set of motivated behaviors that not only provides the child with an exhilarating positive emotion but also exposes them to stimuli they have previously feared. The Anji kindergarten teachers believe that children's play-style or individual experience determines the degree of risk-taking in play, as this is related to children's propensity to risk and past experiences. Children balance their play behavior with regard to their past negative experiences in order to avoid repeating them (Adams, 2001). Earlier research has concluded that children's risky choices and behaviors are influenced by personal characteristics, such as temperament/personality, age, gender, cognition, emotions, motivations, and prior experiences (Nikiforidou, 2017). Moreover, teachers in Anji think that the kindergarten philosophy impacts teachers' understanding of risky play. Anji kindergarten teachers believe that risky play has uncertain or even dangerous factors and is highly challenging and exploratory. Children need to overcome their inner fears, with differences in their individual experiences, and risky play is a motor and psychological challenge for them, in line with the description of risk as to the uncertainty of outcome, whereby a child is required to choose whether to take it or not (Greenfield, 2003). From the teachers' different perceptions of the concept of risky play outlined 
above, it is clear that both Norwegian and Anji teachers bear in mind individual differences among children and the significant role of children's play-styles in risky play from the perspective of children.

Kindergarten teachers in this study agreed that teachers play the roles of supporters and protectors, but their specific approaches to supporting and protecting were different. How caregivers and adults carry out the supervision of children is probably influenced by culture (Sandseter, 2009b). Chinese kindergartens provide humanistic and physical support for children, while Norwegian teachers pay more attention to companionship and emotional communication with children. Norwegian kindergarten teachers are not worried about children bumping into each other during play. Sandseter (2014) also found that most Norwegian early childhood education and care (ECEC) practitioners (both men and women) had few worries when children engaged in risky play. In addition to the above roles, Norwegian teachers believe that rule-making and home coordination are critical, with teachers making rules and communicating with parents. As Tovey (2010) has noted, practitioners share their professional understanding with parents and listen to their concerns. The Anji kindergarten teachers also see the roles of facilitator, sharer, and participant as crucial and encourage young children to take risks while keeping them safe. When children encounter difficulties that are difficult to solve, using language guidance prolongs the process of children's risky play. Children can be organized to share self-protection measures and record their experience of risky play (children draw the play experience down, teachers write down children's descriptions about their play). It is interesting to note that the Anji teachers emphasized the role of participant, but they did not participate in the children's play. In contrast, the Norwegian teachers did not mention engaging but were often involved in the children's play. Perhaps Norwegian teachers took participation in children's play for granted.

The present study showed that teachers mainly rely on their judgment to balance risk and safety and, at the same time, that they ask children to reduce risk through self-protection. Teaching children to take moral responsibility for their actions and learn to anticipate the consequences of such actions in terms of risk to themselves and others has also been a fundamental risk management strategy found in previous studies (Boholm, 2003). Norwegian kindergarten teachers focus on the children's experience in play and ask them to protect themselves. Drawing on the risk "thermostat" model (Adams, 2001), individual past experiences with either rewards or accidents play a significant role in balancing behaviors. Children are also crucial in perceiving dangers, so it is necessary to emphasize children's experiences. The teachers of the Anji kindergarten also proposed regularly checking play materials to eliminate safety hazards and create a relatively safe play environment for children. Adults, given their richer experience, must foresee danger and protect children from risks that are too great for their level of development (Illingworth et al., 1975). Anji kindergarten teachers observe and record children's play, share their observations and recordings (teachers use their cell phones to film clips of children's play that they find interesting or need to discuss) with them after the play, and guide them to reflect on themselves and summarize their failure experiences, for example, asking a child to think about why they always fall off a plank. It is worth noting that Anji 
kindergarten teachers put forward more measures to protect children, which may mean they are more worried about the safety of children. Norwegian teachers find ways to challenge children, while Anji teachers come up with various ways to keep children safe.

In this study, teachers agreed that personal factors could limit the development of risky play, while natural and physical factors are also real problems facing Chinese kindergartens. Norwegian teachers, unlike Chinese teachers think, do not stop risky play if children fall over. As shown in the model (Adams, 2001), accidents are also part of a balancing behaviors system. Children learn to balance risk-taking behaviors from failures as well. Previous researchers (Sandseter et al., 2012) have stated that the fact that children have scrapes and bruises is just part of life. In addition, Norwegian teachers mentioned that a small group of parents has concerns; however, the teachers tended to be more concerned about what was happening and focused on the process, with most parents being supportive of risky play. Little et al. (2011) also found that all the practitioners and parents believed that it was necessary for children to take physical risks when learning new skills, not only for skill development but also for confidence building and learning how to avoid injury. Some teachers think that there are no factors restricting teachers from developing risky play. Nature and outdoor recreation are an important part of Norwegian culture; hence, children playing outside in all sorts of weather is seen as an important and natural part of childhood (Gundersen et al., 2016). Anji kindergarten teachers identified a parental lack of understanding as to the largest limiting factor in developing risky play, requiring long-term communication between teachers and parents. Research has shown that the inclusion of nature enrichment experiences and risk accomplishments in weekly reports to parents could go a long way to ensuring parents and guardians have a positive view of risk (Little \& Derr, 2020). Weather, space, and materials are also significant limitations for Chinese kindergartens.

In conclusion, Norwegian teachers saw the concept of risky play as both rewarding and risky, which is consistent with the model (Adams, 2001), involving both rewards and accidents. Anji teachers saw the individual child as a crucial indicator of risky play, which is also highly related to individual past experiences, as presented in the model (Adams, 2001). Both groups of teachers captured the important feature of uncertainty in risky play. They all valued the role of teachers in supporting and protecting in risky play and took different approaches to support and protection. The Norwegian teachers did not take many measures to protect the children's safety and were more likely to accompany them in risky play. The Anji teachers took various approaches, such as laying down mats and reflecting on the safety hazards of play to protect the children's safety. Norwegian teachers felt that while teachers' fears and concerns may have an impact, there was little to stop them from practicing risky play. In contrast, teachers in Anji experienced multiple limitations, such as lack of parental support and teacher fears. These barriers may prevent Anji teachers from making appropriate risk-taking decisions and become a hindrance to the development of children's risky play. 


\section{Conclusion}

In Norway, there is a cultural context that supports risky play in kindergartens. Norwegian teachers' understanding of risky play is deepened in the course of learning and practice and they explore their perceptions of it, seeing both sides of risky play, rewarding risk, and supporting the practice. Chinese kindergartens lack a support system for the development of risky play. From the exclusion of social ideas to confusion in practice, the lack of cultural and environmental background to communicate "risk-taking" and "urbanized/modernized" kindergartens deprive children of the opportunity to use their natural environment for risky play. In response to the keyword "risk-taking," Anji kindergarten, which initially tried to practice risky play, has made some achievements and has created a new outlook on children and play. This study contributes to the growing body of literature on perceptions of children's risky play from different cultures. It reveals various perspectives of Chinese and Norwegian kindergarten teachers on risky play. Cultural differences were revealed, suggesting that teachers in China took children's injuries and safety more seriously and suggested more thorough safety measures. While Norwegian teachers engage in children's play as part of their daily lives, Chinese teachers emphasize the importance of participation but do not engage in children's play.

Another noteworthy phenomenon is that teachers take some behaviors in risky play for granted, such as participating in young children's play. Influenced by the local culture and surroundings, it is easy for teachers to fall into the "we have always done it this way" situation. This study gave teachers valuable opportunities to reflect on risky play practice and view it from multiple perspectives, enabling them to depart from received ideas and better support risky play. There is no right or wrong risky play practice, but teachers can promote it by reflecting and communicating in different cultural contexts to make it more enjoyable for children. Future research should consider including more diverse countries and exploring teachers' perspectives on outdoor risky play from a wider range of countries. Such research could help infuse teachers with new perspectives and build a diverse and more supportive teacher community.

More samples should be involved to broadly explore their perceptions of risky play. Those teachers who took part may not be representative of all teachers in Norway or China. Future study on kindergartens where teachers may not be familiar with risky play is also needed to find out what conditions in such kindergartens are like and why.

Funding Open Access funding enabled and organized by CAUL and its Member Institutions. ERASMUS, + global mobility program and UTFORSK program.

Open Access This article is licensed under a Creative Commons Attribution 4.0 International License, which permits use, sharing, adaptation, distribution and reproduction in any medium or format, as long as you give appropriate credit to the original author(s) and the source, provide a link to the Creative Commons licence, and indicate if changes were made. The images or other third party material in this article are included in the article's Creative Commons licence, unless indicated otherwise in a credit line to the material. If material is not included in the article's Creative Commons licence and your intended use is not permitted by statutory regulation or exceeds the permitted use, you will need to obtain permission 
directly from the copyright holder. To view a copy of this licence, visit http://creativecommons.org/licen ses/by/4.0/.

\section{References}

Adams, J. (2001). Risk. Routledge.

Aldis, O. (2013). Play fighting. Elsevier.

Apter, M. J. (2007). Danger: Our quest for excitement. Oneworld Publications Limited.

Ball, D. J., Gill, T., \& Spiegal, B. (2008). Managing risk in play provision: implementation guide. The Department for Children, Schools and Families (DCSF) and the Department for Culture, Media and Sport (DCMS).

Beyer, K., Bizub, J., Szabo, A., Heller, B., Kistner, A., Shawgo, E., \& Zetts, C. (2015). Development and validation of the attitudes toward outdoor play scales for children. Social Science and Medicine, 133(1), 253-260. https://doi.org/10.1016/j.socscimed.2014.10.033

Bilton, H. (2020). Values stop play? Teachers' attitudes to the early years outdoor environment. Early Child Development and Care, 190(1), 12-20. https://doi.org/10.1080/03004430.2019.1653548

Boholm, A. (2003). The cultural nature of risk: Can there be an anthropology of uncertainty? Ethnos, 68(2), 159-178. https://doi.org/10.1080/0014184032000097722

Brussoni, M., Gibbons, R., Gray, C., Ishikawa, T., Sandseter, E. B. H., Bienenstock, A., Chabot, G., Fuselli, P., Herrington, S., Janssen, I., Pickett, W., Power, M., Stanger, N., Sampson, M., \& Tremblay, M. S. (2015). What is the relationship between risky outdoor play and health in children? A systematic review. International Journal of Environmental Research and Public Health, 12(6), 6423-6454. https://doi.org/10.3390/ijerph120606423

Brussoni, M., Olsen, L. L., Pike, I., \& Sleet, D. A. (2012). Risky play and children's safety: Balancing priorities for optimal child development. International Journal of Environmental Research and Public Health, 9(9), 3134-3148. https://doi.org/10.3390/ijerph9093134

Castro, E. L. L. (2012). The value of risky play at natural outdoor environment to develop children's relationship. Unpublished master's thesis. Oslo and Akershus University College of Applied Sciences. http://www.hioa.no/content/view/full/21823

Cheng, X. (2017). Anji Play on the Road to Reform I A profound revolution in children's play. Anji Early Childhood Education. http://www.ajplaychina.com/content/article/article_detail/id/2937/cid/39.

Frost, J. L., Wortham, S. C., \& Reifel, R. S.Translator:Tang Xiaojuan,Zhang Yin,Shi Mingjie (2015). Play and child development. Beijing Mechanical Industry Press (in Chinese).

Gibson, E. J. (1988). Exploratory behavior in the development of perceiving, acting, and the acquiring of knowledge. Annual Review of Psychology, 39(1), 1-41. https://doi.org/10.1146/annurev.psych. 39.1 .1

Greenfield, C. (2003). Outdoor play: The case for risks and challenges in children's learning and development. Safekids News, 21(5), 5.

Greenfield, C. (2004). Transcript: 'Can run, play on bikes, jump the zoom slide, and play on the swings': Exploring the value of outdoor play. Australasian Journal of Early Childhood, 29(2), 1-5.

Gundersen, V., Skår, M., O’Brien, L., Wold, L., \& Follo, G. (2016). Children and nearby nature: A nationwide parental survey from Norway. Urban Forestry and Urban Greening, 17(1), 116-125. https://doi.org/10.1016/j.ufug.2016.04.002

Illingworth, C., Brennan, P., Jay, A., Al-Rawi, F., \& Collick, M. (1975). 200 injuries caused by playground equipment. British Medical Journal, 4(1), 332-334.

Kelley, P., Hood, S., \& Mayall, B. (1998). Children, parents and risk. Health \&amp; Social Care in the Community, 6(1), 16-24.

Little, H. (2010). Finding the balance: early childhood practitioners' views on risk, challenge and safety in outdoor play settings. Australia: Australian Association for Research in Education (AARE).

Little, H., \& Derr, V. (2020). The influence of nature on a child's development: connecting the outcomes of human attachment and place attachment. Research Handbook on Childhood nature: Assemblages of Childhood and Nature Research, 151-178.

Little, H. (2006). Children's risk-taking behaviour: Implications for early childhood policy and practice. Taylor and Francis. 
Little, H., Sandseter, E. B. H., \& Wyver, S. (2012). Early childhood teachers' beliefs about children's risky play in Australia and Norway. Contemporary Issues in Early Childhood, 13(4), 300-316.

Little, H., \& Wyver, S. (2008). Outdoor play: Does avoiding the risks reduce the benefits? Australasian Journal of Early Childhood, 33(2), 33-40.

Little, H., Wyver, S., \& Gibson, F. (2011). The influence of play context and adult attitudes on young children's physical risk-taking during outdoor play. European Early Childhood Education Research Journal, 19(1), 113-131.

McFarland, L., \& Laird, S. G. (2018). Parents' and early childhood educators' attitudes and practices in relation to children's outdoor risky Play. Early Childhood Education Journal, 46(2), 159-168. https://doi.org/10.1007/s10643-017-0856-8

McGinnis, J. (2003). Adventure playgrounds and outdoor safety issues. Child Care Information Exchange, 46-50.

Nikiforidou, Z. (2017). 'It is riskier': Preschoolers' reasoning of risky situations. European Early Childhood Education Research Journal, 25(4), 612-623.

Orestes, L. A. (2015). The Benefits of Risky Play and Adult Influence in Children's Risky Play. (Unpublished Master's thesis). University of Victoria.

Renick, S. E. (2009). Exploring early childhood teachers' beliefs and practices about preschool outdoor play: A case study. ProQuest Dissertations Publishing.

Sandseter, E. B. H., \& Kennair, L. E. O. (2011). Children's risky play from an evolutionary perspective: The anti-phobic effects of thrilling experiences. Evolutionary psychology, 9(2), https://doi.org/10. 1177/147470491100900212

Sandseter, E. B. H. (2009a). Characteristics of risky play. Journal of Adventure Education and Outdoor Learning, 9(1), 3-21.

Sandseter, E. B. H. (2009b). Risky play and risk management in Norwegian preschools-A qualitative observational study. Safety Science Monitor, 13(1), 2.

Sandseter, E. B. H. (2014). Early childhood education and care practitioners' perceptions of children's risky play; examining the influence of personality and gender. Early Child Development and Care, 184(3), 434-449.

Sandseter, E. B. H., Little, H., \& Wyver, S. (2012). Do theory and pedagogy have an impact on provisions for outdoor learning? A comparison of approaches in Australia and Norway. Journal of Adventure Education and Outdoor Learning, 12(3), 167-182.

Sandseter, E. B. H., \& Sando, O. J. (2016). "We don't allow children to climb trees": How a focus on safety affects Norwegian children's play in early-childhood education and care settings. American Journal of Play, 8(2), 178.

Sawyers, J. K. (1994). The preschool playground: Developing skills through outdoor play. Journal of Physical Education, Recreation and Dance, 65(6), 31-33.

Stephenson, A. (2003). Physical risk-taking: Dangerous or endangered? Early Years, 23(1), 35-43.

Tovey, H. (2010). Playing on the edge: perceptions of risk and danger in outdoor play. Play and learning in the early years, 79-94. SAGE publications Ltd.

White, R. (1997). Sometimes, You Just Gotta Make Mud Pies. Children's Adventure Play Gardens. White Hutchinson Leisure \& Learning Group. http://www.whitehutchinson.com/leisure/articles/84.shtml

Publisher's Note Springer Nature remains neutral with regard to jurisdictional claims in published maps and institutional affiliations. 